\title{
Contribuição teórico-conceitual para a pesquisa avaliativa no contexto de vigilância da saúde
}

\author{
Theoretical and conceptual contribution \\ to evaluative research in health surveillance context
}

Antônio Luis Vicente Arreaza ${ }^{1}$

JoséCássio de M oraes ${ }^{2}$

\footnotetext{
${ }^{1}$ Instituto Adolfo Lutz, Coordenadoria de Controle deDoenças, Secretaria de Estado da SaúdedeSão Paulo. Rua Silva Jardim 90, Vila Nova. 11015-020 Santos SP.

alvarreaza@uol.com.br ${ }^{2}$ Departamento deM edicina Social, Faculdade de Ciências M édicas, Santa Casa de São Paulo.
}

Abstract I nitially this article revises some of the conceptual and operational elements on evaluative research by gathering knowledge and action fields on public health practices. Such concepts aretaken according to a wider conception of quality. Then, the article intends to arrange a theoretical model design considering the proposition for implementation of health surveillanceactions. An image-objective definition of organization and integration of health polices and practices based on hierarchic and local logic also take place. Finally, becomings and challengesaround thethe ory in the health evaluation field turn to be the aim of our reflection in order to enable the production of knowledge and approaches to construct logic models which reveals the complexity of interventionist objects as well as its transforming nature of social practices.

Key words Evaluative research, $\mathrm{H}$ ealth surveillance, $\mathrm{H}$ ealth practices and services
Resumo 0 presente artigo revisita inicialmente alguns dos elementos conceituais e operacionais sobre pesquisa avaliativa, em consonância com uma concepção ampliada de qualidade, reunindo saberes e campos de ação no âmbito das práticas de Saúde Pública. Em seguida, buscamos viabilizar o desenho de um modelo teórico tendo em vista a proposta de implementação das ações de vigilância da saúde, como na definição de uma imagem-objetivo da organização e integração das políticas e práticas de saúde sob uma lógica hierarquizada e regionalizada. Por fim, refletimos sobre os devires e desafios em torno da importância da teoria no campo da avaliação em saúde, produzindo saberes e abordagens para construção de modelos lógicos que relevem a complexidade dos objetos de intervenção e sua natureza de prática social transformadora.

Palavras-chave Pesquisa avaliativa, Vigilância da saúde, Práticas e serviços de saúde 


\section{Introdução}

As relações entreasnecessidades epráticas desaúde podem ser apreendidas a partir de duas vertentes principais: a primeira consiste na busca de seus significados políticos, socioeconômicos, culturais eideológicos, bem como da especificidade dessas relações em sociedades concretas; a segunda diz respeito à capacidade das práticas de modificarem uma dada situação-problema atendendo ou não às necessidades de saúde de uma determinada coletividade, ou seja, refere-seessencialmenteà discussão sobre suas características e seus resultados alcançados. N esta última perspectiva, a temática da avaliação ganha relevância tanto em relação à possibilidadee necessidade de intervenções capazes de modificar certos quadros sanitários, quanto em face à verificação das dificuldades enfrentadas por essas mesmas práticas para alterarem os coeficientes de morbimortalidade, dentre outras tantas circunstâncias ${ }^{1}$.

Sob esse prisma, o campo da Saúde Pública tem privilegiado em seus modelos e pautas de atuação os seguintes objetos de ação em saúde: políticas sociais e práticas institucionais de saúde; organização e regulação dos recursos e processos produtivos da sociedade e meios e modos de produção tecnológica de intervenção. Dessa forma, enquanto âmbito de práticas de saúde, vem incorporando saberesinterdisciplinarescom amplas interfaces de fertilidade, seja na execução desuas funções essenciais ou no exercício de suas atribuições possíveis edesejáveis. A SaúdePública contempla assim tanto a ação do Estado quanto o compromisso da sociedade para a produção de ambientes e populações saudáveis através de atividades gerais e especial izadas².

Entendemos, pois, a Saúde Pública como uma prática social de natureza interdisciplinar para proteger e melhorar a saúde das pessoas, incluindo a responsabilidade de assegurar 0 acesso a cuidadosintegrais desaúdee sua qualidade. N esse sentido, algumas das principais atribuições de saúde pública são o monitoramento e análise da situação de saúde; a vigilância e controle deagravos, riscos e danos; o fortalecimento institucional do planejamento e gestão; a garantia e meIhoria da qualidade dos serviços de saúdee a pesquisa e implementação de soluções criativas e inovadoras ${ }^{3}$.

Já o modelo de vigilância da saúde, ao enfatizar as condições de vida, estabelecea sua vez uma ampliação do conceito operacional de vigilância em Saúde Pública, integrando as práticas coletivas eindividuais em diferentes dimen sões das ne- cessidades de saúde, que incluem além do controle de riscos e danos também os determinantes ecossociais, subsidiando amplamente a gerência no processo de definição dos problemas prioritários e das possíveis respostas sociais para enfrentá-los4.

Ao se considerar a possibilidade de ações voltadas para o controle de causas, riscos e danos, pensava-se na perspectiva de incorporar a promoção e proteção da saúde ao conjunto articulado de medidas jáadotadas pelo SUS. Logo, a oferta organizada e ações programáticas em saúde poderiam searticular com as atividades de vigilância sanitária e epidemiológica como de assistência médico-hospitalar. Da mesma forma, tais ações setoriais seriam capazes de se integrar à intervenção social organizada e às políticas intersetoriais ou transetoriais que configuram o espaço da promoção da saúde. Se essas fossem efetivamente implementadas tomando a saúde e qualidade de vida como referentes fundamentais, a ação transintersetorial consequente estaria voltada para as políticas públicas saudáveis coerentes com o movimento de promoção da saúde 5 .

Lembramos que os model os assistenciais podem ser considerados como um dado modo de combinar tecnologias para intervir sobre problemas eatender necessidades sociais de saúde, sendo uma maneira de organizar os meios de trabaIho utilizados nos serviços ou programas de saúde. Sinalizam como melhor integrar os saberes e instrumentos disponíveis para resolver os problemas de saúde individuais e coletivos, incorporando uma lógica que orienta as práticas sobre as "demandas potenciais" de saúde. Aliás, adotamos também a expressão utilizada por Paim como "modos tecnológicos de intervenção em saúde" para designar o modelo de vigilância da saúde.

Para o desenvolvimento deste trabalho e das reflexões daí originadas na construção de um modelo lógico para o processo avaliativo ede sua operacionalização no âmbito da vigilância da saúde, partimos do pressuposto de que o campo de atuação da Saúde Pública, enquanto rede de relações entre atores sociais comprometidos com a produção de valores de uso, demarcaria espaços definidos por demandas complexas das organizações para onde convergem saberes e práticas que buscariam em outras áreas do saber ou profissionais instrumentos e tecnologias para o cumprimento de suas tarefas teóricas e práticas na condução do processo de trabalho produtivo e integrado ${ }^{6}$. Em que as articulações entre as ações de saúde representariam os meios estratégicos para produção dos cuidados e atenção à saúde bem como as relações 
intersubjetivas representariam as práticas comunicativas na constituição de novos sujeitos produtores de saúde. A adesão e a intercomunicação entre os agentes e usuários dos serviços, como a interação multiprofissional do trabalho em equipe são componentes indispensáveis para o trabalho gestor na produção e organização da atenção à saúde e da sua qualidade em termos de integralidade e efetividade das ações?.

Neste contexto, o presente artigo revisita inicialmentealguns doselementos conceituais eoperacionais sobre a pesquisa avaliativa, em consonância com uma concepção ampliada de qualidade, reunindo saberes e campos de ação no âmbito das práticas de Saúde Pública. Em seguida, buscamos viabilizar o desenho de um modelo te órico tendo em vista a proposta de implementação das ações de vigilância da saúde, como na definição de uma imagem-objetivo da organização e integração das políticas e práticas de saúde sob uma lógica hierarquizada eregionalizada. Por fim, refletimos sobre os devires e desafios em torno da importância da teoria no campo da avaliação em saúde, produzindo saberes e abordagens para a construção de modelos lógicos que relevem a complexidade dos objetos deintervenção e sua natureza de prática social transformadora.

Pesquisa avaliativa:

conceitos, atributos e características

A avaliação como um componente fundamental das práticas de saúde pública pode ser entendida a priori como uma forma de valoração sistemática que se baseia no emprego de alternativas metodológicas que servem para identificar, obter e proporcionar a informação pertinente ejulgar o mérito e o valor de algo de modo justificável, abordando as atividades, características e re sultados das ações em saúde com o objetivo de subsidiar a tomada de decisão sobre programações pertinentes ${ }^{8}$.

No que tange à pesquisa avaliativa, podemos apreendê-la como a aplicação sistemática de procedimentos oriundos das ciências sociais para fazer julgamentos sobre os programas de intervenção, analisando as bases teóricas, o processo operacional e a implementação dos mesmos em sua interface com o contexto no qual os constituem. Conforme as perspectivas dos diferentes atores envolvidos no programa, as estratégias de pesquisa avaliativa podem desdobrar-se na análise estratégica, de implantação, de desempenho e dos efeitos das ações?.
Asinterações entre atores, vivências eprocessos que constituem a prática de atuação dos serviços contribuem para uma concepção mais abrangente do que aquela restrita ao uso instrumental dos resultados da ação ${ }^{10,11}$. N essa perspectiva, o escopo da avaliação sobrepuja a dimensão objetivada da ação, tomando por objeto essencial as ações programáticas em saúde, as intervenções sociais planejadas, como também as representações articuladas pel os atores na atuação dos serviços de saúde $e^{10,12}$.

O campo da avaliação comporta uma multiplicidade de possibilidades de recortes do real, formas de definir abordagens, dimensões e atributos para as práticas avaliativas, que refletem, em al guma medida, as escolhas teóricas e pontos de vista dos diferentes atores implicados que correspondem às suas posições no campo e espaços a que pertencem, como à sua formação intelectual, visão crítica e trajetória social ${ }^{12}$.

Posto isto, inferimos que as necessidades de saúde podem ser objeto de graus distintos de controle de causas, riscos ou danos, dependendo da fase de desenvolvimento da história de um agravo à saúde e das características do modelo assistencial implementado. Para cada um desses níveis de controle, existem diversas possibilidades de intervenção cujos atributos têm sido considerados como instrumentos indispensáveis para a avaliação das práticas e serviços de saú$\mathrm{de}^{12}$ (Figura 1).

Logo a primeira preocupação do gestor em relação a uma intervenção sanitária está relacionada com a magnitude da oferta das ações e serviços para atender às necessidades da população-alvo. N esse caso, a cobertura pode ser pensada em relação a intervenções de diversos tipos, desde aquelas voltadas ao controlede riscos edanos até as vinculadas à promoção da saúde, tendo por referência um sistema estruturado para o atendimento da demanda espontânea ou estando orientado à oferta organizada e às ações programáticas.

Jáa acessibilidade tem sido definida como uma relação entreos recursos depoder do usuário (econômicos, social e cultural) e os obstáculos colocados pelos serviços (geográficos, organizacionais e de utilização), cujo desfecho pode interferir negativamente no manejo do problema de saúde em questão $0^{13}$. Contudo, a oferta organizada voltada para enfrentar um dado problema pode ampliar o acesso da população aos diversos níveis do cuidado como aumentar também a cobertura real das referidas ações necessárias.

A segunda característica relevante das práticas de saúde diz respeito aos possíveis efeitos das 


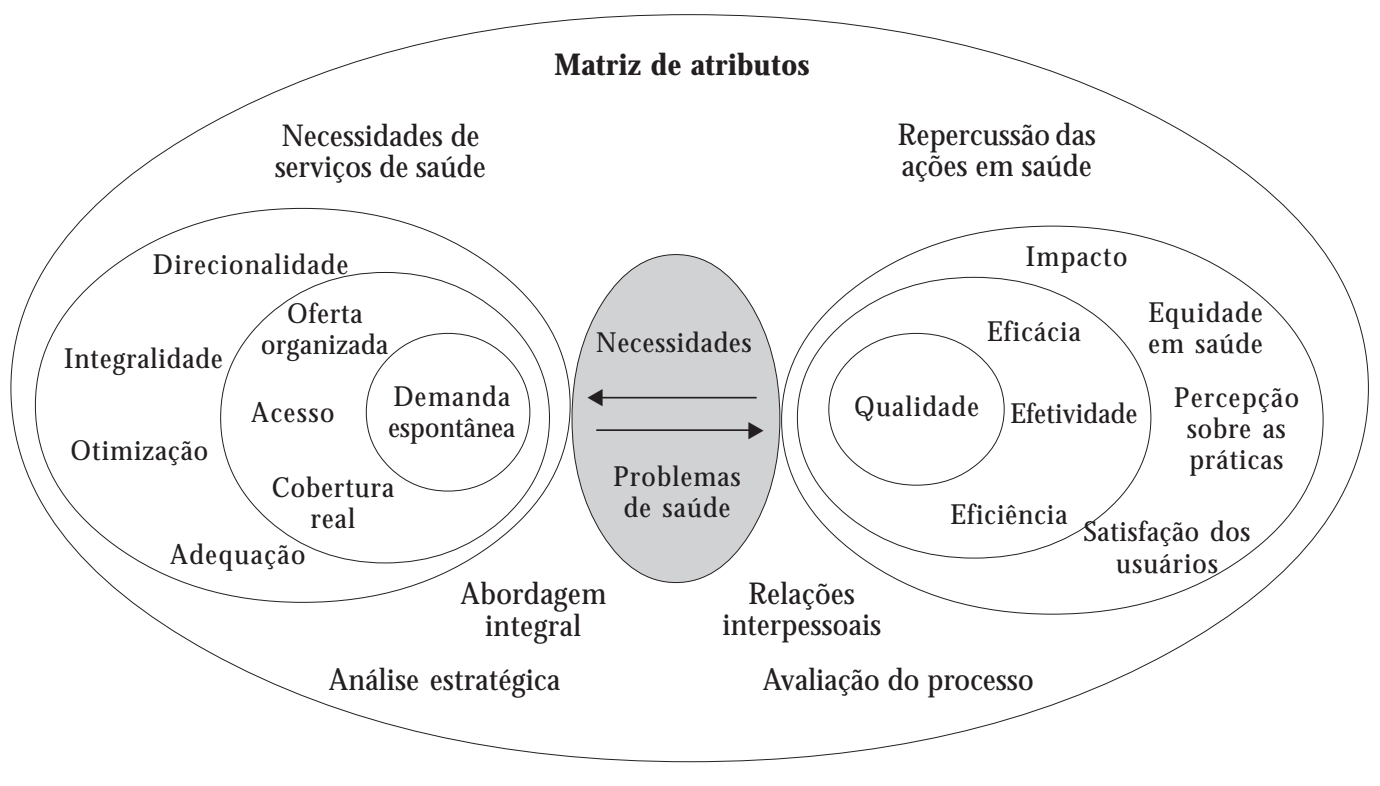

Figura 1. M atriz de atributos ou características para avaliação das práticas e serviços de saúde.

Adaptação: Vieira-da-Silva12.

ações sobre o estado de saúde dos indivíduos ou coletividades. A distinção entre eficácia como efeito deuma intervenção em situação experimental e efetividade como o efeito da mesma em sistemas operacionais vem semantendo ao longo dos anos ${ }^{14,15}$. Atribuímos, então, à definição ampliada de efetividadea seguinte concepção: uma transformação concreta obtida no estado de saúde das pessoas por meio do trabalho coletivo eintegrado. Já o conceito de impacto tem sido utilizado, de modo mais apropriado, para designar o resultado de uma ação em relação a grandes grupos populacionais ou em intervalos de tempo prolongados, como também a repercussão no perfil epidemiológico e nas condições de saúde da população não coberta pelo sistema assistencial epreventivo.

Quanto à qualidade técnica, compreende a adequação das ações ao conhecimento técnico e científico vigenteno cuidado da saúde do paciente ${ }^{16}$ ou a aplicação apropriada do saber e tecnologias disponíveis, buscando otimizar as práticas de atenção integral à saúde. A análise estraté gica explicita, por sua vez, se as atividades propostas são pertinentes aos objetivos e problemas desaúde, isto é, a direcionalidadee a consistência do plano implementado. Não obstante, a integralidade caracteriza-se como uma apreensão ampliada das necessidades de saúde em que a oferta dos serviços deva estar sintonizada com o contexto específico de cada encontro do sujeito com a equipe de saúde ${ }^{17}$.

Em relação à equidade, refere-se à distribuição justa e razoável dos recursos de acordo com as necessidades de saúde da população, tornando-os bens e produtos aceitáveis el egítimos para os membros de uma coletividade. 0 que equivale a dizer que devemos dar oportunidades diferentes aos desiguais e priorizar para a intervenção sanitária os grupos sociais mais vulneráveis às fragilidades da vida. A equidade perpassa e transita por quase todos os demais atributos e, assim, podemos pensá-la no acesso, acolhimento, integralidade, efetividade, qualidade técnica, aceitabilidadee, entre outros.

Por fim, as relações interpessoais correspondem à percepção e satisfação dos usuários sobre as práticas, o respeito à privacidade e outros direitos individuais e às relações técnico-sociais de trabalho entre os agentes das ações, como componentes da qualidade de assistência integral e promoção da saúde. Em algumas circunstâncias, 
a reorganização programática pode promover a integração entre os diversos atores sociais na gestão da saúde, de tal forma que o próprio desenvolvimento das relações interpessoais passa a ser um resultado importante no contexto das atividades implementadas ${ }^{12}$.

Sob esse aspecto, a prática do trabalho integrado em equipe pode ser apreendida através da adesão e comunicação entre os agentes do trabaIho, do aporte das especificidades nucleares em seus campos de ação e da interdependência da atuação e autonomia profissional; à medida que a equipe configura o seu trabal ho nesta direção, tende a construir um projeto comum que setorna o eixo em torno do qual os diferentes agentes realizam as suas atividades produtivas articuladas aos demais produtores de saúde ${ }^{18}$.

Relevamos, todavia, que diferentes atores e agentes da saúde no processo de avaliação dos serviços tendem a valorizar aspectos distintos quando estabelecem seus critérios de juízos no aporte da qualidade das práticas de saúde ${ }^{19}$. De mocratizar a participação detodos na gestão, com seus objetivos e percepções, flexibilizando o processo de tomada de decisão, vem ao encontro do poder ampliado da avaliação para descortinar as diversas características de uma mesma intervenção e de seus resultados al cançados.

Modelo teórico:

níveis, dimensões e componentes

O desenho do modelo teórico, explicitando sua racionalidade subjacente, incorpora as necessidades, o problema, o contexto e os componentes essenciais das políticas e práticas de saúde para produzir, de forma articulada e integrada, os resultados desejáveis para todos os atores envolvidos no processo. Trata-se de uma série de níveis organizados de forma hierárquica, em que os componentes do modelo apresentam, concisamente, o seu fundamento lógico-operacional do sistema estruturado ${ }^{20}$. 0 objetivo primordial é proporcionar um aporte dos processos implicados na produção dos resultados esperados das intervenções praticadas, como valorizar a interface entre os efeitos das políticas eo impacto gerado na coletividade.

Nesse sentido, buscamos construir um modelo visando dimensionar os diferentes níveis organizacionais das políticas e práticas na perspectiva da proposta de vigilância da saúde, em que os atributos de acesso, integralidade, efetividade, qual idade equidade vinculam-se às intervenções de promoção, proteção e recuperação da saúde, e tendo como eixo de prioridades as ações de controle sobre as causas, riscos e danos $^{21}$ (Figura 2). Já o conceito de modelo assistencial adotado é aquele que o considera como combinaçõestecnológicas para intervir sobre problemas enecessidades de saúde, incluindo as ações sobreo ambiente, condições de vida, grupos sociais e bens e produtos de consumo de interesse à saúde, alicerçando-se amplamente tanto em atividades de educação e comunicação social como na formulação de políticas públicas saudáveis ${ }^{5}$.

A partir desse modelo teórico descrito, que correspondendo à organização das políticas epráticas de saúde sob uma lógica hierarquizada eregionalizada, intentamos dimensionar os níveis de contexto político, gestão do setor saúde epráticas assistenciais, como de suas respectivas dimensões e componentes, sumarizados da seguinte forma: plano e capacidade de governo e sua governabilidade; planejamento e gestão em Saúde Pública; integralidade das ações em promoção da saúde; vigilância e controle de causas, riscos e danos; abordagem integral à saúde através de práticas multidisciplinares e efetividade das práticas no estado de saúde da população ${ }^{21}$ (Figura 2).

Em nível decontexto político, enfatizamosque a disposição para priorizar a saúde se materializa tanto no plano de governo como nos discursos dos atores do setor saúde, isto é, considerando também a coerência entre os problemas priorizados e ações propostas. Além disso, relevamos o desenvolvimento de políticas intersetoriais com planejamento integrado ou comitê misto entre dois ou mais setores do governo; lembramos ainda, da importância de disponibilizar orçamento próprio para implantação dos projetos de promoção da saúde.

Quanto à capacidade do governo, nos referimos mais singularmente ao perfil dos gestores e dirigentes com liderança e formação em Saúde Coletiva, como na adequação do quadro técnico às necessidades do sistema de saúde. Por sua vez, a governabilidade com base de apoio político e da sociedade civil organizada consolida-se no âmbito das relações entre gestores na definição e implementação de políticas públicas, com destaque para as propostas de soluções inovadoras de gestão e modelos assistenciais. Todavia, a adesão dos agentes das ações, como participantes na gestão e sua satisfação no trabal ho desenvolvido, são elementos democráticos e equitativos para o fortalecimento da capacidade institucional do campo social da Saúde Pública.

Face ao fortalecimento institucional de gestão do setor saúde, aportamos à utilização do planejamento situacional como um instrumento indis- 


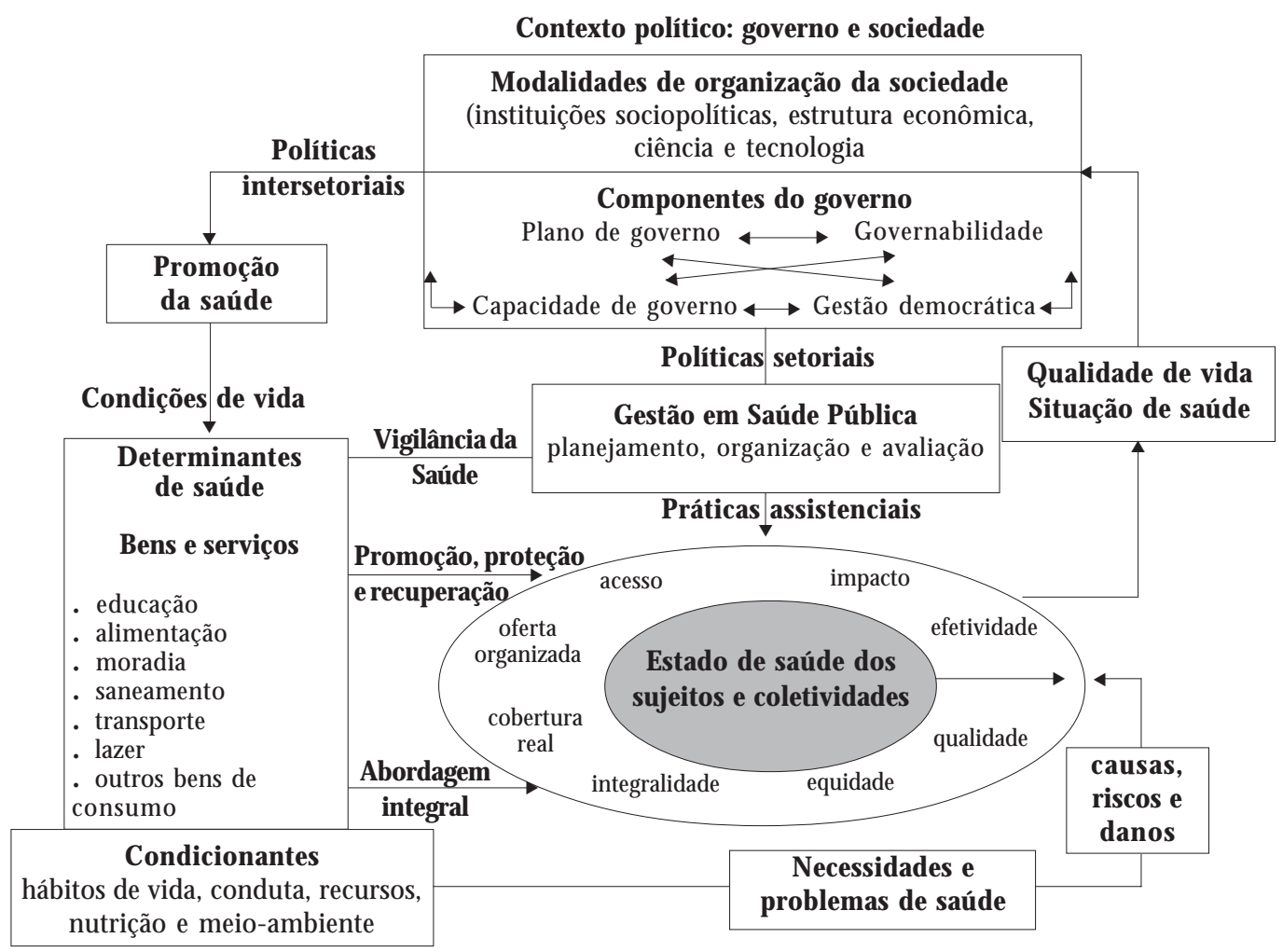

Figura 2. M odelo teórico dos diferentes níveis organizacionais das políticas e práticas de saúde sob uma lógica hierarquizada e regionalizada.

Adaptação: Vieira-da-Silva ${ }^{21}$.

pensável para o gerenciamento das estratégias de descentralização e integralidade das práticas de Saúde Pública. Não obstante, a avaliação e o seu produto são imprescindíveis para o processo de tomada de decisões e acompanhamento das atividades implementadas, características particulares para a sua institucionalização. Já a despeito da organização setorial, sublinhamosaincorporação das ações programáticas e oferta de serviços adequados ao perfil epidemiológico e social das coletividades, implementando também os programas prioritários com repercussão em nível nacional.

Por fim, no contexto das práticas assistenciais, faz-se pertinente a existência de ações intersetoriais voltadas para as necessidades e problemas desaúde, bem como de práticas de vigilância para o monitoramento da situação de saúde e tomada de decisão descentralizada. Logo, ressaltamos a importância da articulação e integração entre os níveis de promoção, prevenção e recuperação para os agravos priorizados no âmbito local, com direcional idadeeconsistência en tre ações real izadas e problemas abordados. Além disso, devemos lembrar que as práticas desenvolvidas na abordagem integral à saúde devem estar também dirigidas para cada encontro específico dos sujeitos com a equipe dos serviços de saúde.

Acrescenta-se a isto que a organização e supervisão em equipe do processo de trabalho produtivo ea participação dos usuários na definição de prioridades do cuidado à saúde, como parte das práticas cotidianas da gerência de serviços descentralizados, devem ser consideradas como instrumentos importantes na cogestão de práticas assistenciais e apreensão de respostas efetivamente dadas no nível local. Isso reflete de certa forma a capacidade técnico-política e social do gestor em ampliar o seu poder decisório e mediação na implementação das ações de saúde, como no acompanhamento do impacto a ser produzi- 
do no estado de saúde dos sujeitos e coletividade ao longo do tempo.

No caso da verificação de efetividade das práticas de saúde, utilizamos normalmente indicadores descritivos para medir a evolução da morbimortalidade de diferentes doenças e agravos de importância em Saúde Pública. Indicadores, além de expressarem medidas de impacto sobre a saúde da população, devem mensurar, de forma integrada, o acesso, oferta, cobertura, qualidade, eficiência e efetividade dos processos implementados, sendo que o produto dos mesmos constitui-se numa ferramenta importante para a formação de opinião e tomada de decisões. Enfim, os atributos buscam garantir que os indicadores expressem as medidas que considerem a abrangência multidimensional do fenômeno saúdedoença e de suas intervenções como processos complexos, multifacetados e intercambiantes.

Todavia, argumentamos que, no aporte das dimensões complexas das práticas de saúde, abordadas numa pesquisa avaliativa, tem-se como consequência a produção de resultados úteis e otimizados para que se possa intervir na estrutura técnico-operacional dos serviços frente às necessidades e problemas de saúde atendidos, isto é, interativamente, como tomamos o todo pelas partes e as partes pelo todo ${ }^{22}$.

Reflexões críticas:

devires, desafios e possibilidades

Dentre os principais desafios e debates presentes no campo da avaliação em saúde, um dos primeiros a ser reconhecidos é que as ações e práticas de saúde têm natureza social e histórica, o que não pode e nem deve ser negligenciado por quem pretendeavaliá-las. Sendo fato que o objeto da avaliação se modifica em função do tempo e do seu contexto, também o é que a própria pesquisa transforma o objeto avaliado naquilo que faz parte da sua essência, tomado e proble matizado no processo de avaliação. Outro desafio a ser considerado é a dimensão subjetiva da avaliação a despeito de um julgamento sobre uma dada intervenção, devendo-seter em mente que qualquer juízo de valor está orientado por uma visão de mundo do sujeito da pesquisa.

Em vista disso, énecessário trazer para a epistemologia a reflexão crítica de como se faz a produção de saberes de objetos cambiantes e de como se estabelecem relações entre teoria e empiria num campo em que a subjetividadee práxis são constitutivas do próprio objeto. Para isso, os diferentes atores do saber e ação precisam se dedicar aos problemas concretos da pesquisa, para pensar que especificidades relacionadas ao campo da avaliação devem ser consideradas na elaboração de modelos teóricos e no desenho de estratégias de investigação, de sorte que a epistemologia possa contribuir de forma mais efetiva para enriquecer o debate sobre a importância da teoria no campo da avaliação em saúde ${ }^{23}$.

H ortale et al. ${ }^{24}$, propondo um modelo para organização dos serviços, salientaram que permanecia existindo uma dicotomia entre a compreensão atual dos determinantes de saúde e as prioridades definidas para os serviços pelas políticas de saúde. Isso deveria ser decorrência da utilização persistente de quadros de referência ou model os insuficientes eincipientes de conceituação daqueles condicionantes para uma concepção mais abrangente dessas políticas e práticas de saúde.

Carvalho et al. ${ }^{25}$ argumentam, por sua vez, que as demandas e tensões em torno do uso de evidências em políticas de saúde, como parte de uma gestão orientada apenas por resultados, indicam um distanciamento entre as ditas concepções pragmáticas ea natureza complexa das ações de promoção da saúde. Refletindo assim, os desafios postos no aporte de perfis de efetividadee eficiência confrontados pelos os diferentes atores envolvidos com a organização das ações intersetoriais em saúde. Logo, na explicitação das mudanças sociais esperadas pelos atores envolvidos nesse processo, devem-se abarcar então os marcos teóricos pertinentes para a apreensão das interfaces entre as práticas e ações afins frente aos diferentes contextos e ou políticas transetoriais.

De um modo geral, melhorar a saúde da população em busca de equidade ebem-estar social é o objetivo central dos sistemas de saúde de diferentes países em todo o mundo; no entanto, atingir essa meta é um processo complexo que envolve objetivos intermediários e ações intersetoriais. N ecessitando também do aprimoramento de saberes e práticas sobre os determinantes de saúde para que possam contribuir na superação das desigual dades como no al cance da qualidade de vida para todos ${ }^{26}$.

A princípio, o campo da promoção da saúde, delineando-se como uma política pública que deve percorrer o conjunto das ações e projetos em saúde, apresenta-se em todos os níveis de complexidade da gestão e atenção do sistema de saúde brasileiro. Tal política, ao deslocar o foco dos profissionais de saúde dos danos e doença 
para a potencialidade dos sujeitos na sua (re)criação do próprio andar de vida, objetiva a produção de graus e formas de autonomia e de valor de uso durante o processo do cuidado à saúde. Comprometida, portanto, com serviçose ações que coloquem usuários e profissionais como protagonistas na organização do processo produtivo de saúde e na produção de sujeitos e seus modos de vida ${ }^{27}$.

Trata-se de um compromisso ético do SUS com a integralidade e gestão participativa, uma vez que se devem estabelecer modos de atenção e gestão das políticas públicas que operem na indissociabilidade entre promoção e proteção da saúde e entre as necessidades sociais e ações do Estado. Essa postura expressa o compromisso em reorganizar os serviços de saúde e com a inclusão da coletividade na construção e gestão de seus projetos e processos de trabalho, conformando colegiados que não se devem deixar burocratizar nem tecnocratizar.

Desde os anos noventa, Schraiber et al. ${ }^{7}$ já colocavam que, no cotidiano da atenção à saúde, a construção de um projeto assistencial comum a todos da equipe de trabalho, por meio do agir comunicativo, requer tolerâncias às diversidades, mudanças e críticas e, assim, compartilhar a sua atuação com os outros agentes, participando dos momentos de planejamento, execução e avaliação, para que possam enfrentar, conjuntamente, os problemas decorrentes do processo saúdedoença em indivíduos e nas populações. Lembrando apenas que o desempenho das organizações de saúde depende em parte dos contextos políticos, econômicos e socioculturais e não somente de modificações técnico-gerenciais, ainda que estas interfiram na capacidade efetiva dos serviços em melhorar a saúde das pessoas.

Aliás, a participação e controle social como expressões dinâmicas desses contextos, com seus enfoques político-ideológicos e interfaces com o Estado, devem ser sempre considerados como forma de aproximação às necessidades reais dos sujeitos e comunidades para seintervir sobre os problemas de saúde de forma mais efetiva e concreta, sendo que o cidadão-usuário se insere no âmbito dos processos decisórios e avaliativos, deixando o Estado de ser o mediador infalível do interesse coletivo e bem comum dos sujeitos sociais ${ }^{18}$.

Não obstante, entendemos a avaliação como um instrumento de mudanças da gestão que, ao incorporar as questões erepresentações dos principais grupos de interesse, amplia tanto a inclusão dos diferentes pontos de vista como as possibilidades de utilização dos resultados pel os envolvidos na recomposição de suas práticase eações em saúde. No campo de atuação da avaliação, convergem outros dispositivos, como o planejamento, comunicação e educação em saúde, voltados para a superação de questões intrínsecas aos serviços e programas, a criação e desenvolvimento de redes de compromisso entre os grupos implicados, além de promover a capacitação dos envolvidos na condução de suas atribuições ${ }^{28}$.

Desse modo, a instauração de um processo avaliativo que garanta a inclusão de atores externos à equipe e na gestão dos programas ou serviços, através da incorporação de outros grupos de inter esse como usuários, comunidades e gestores de outros serviços, instituiria uma rede de compromissos de sujeitos produtores e certo controle sobre a efetivação de alterações definidas durante o processo sobre a lógica operacional do objeto de intervenção avaliado.

Em síntese, na aproximação entrea produção simultânea de bens eserviços e a criação de espaços para a constituição desujeitos ecoletivos, agregam-se os interesses e objetivos dos sujeitos e os inerentesà organização no mesmo nível de considerações relativas à produção de valores de uso no cuidado à saúde 6 . Assim, todo equalquer instrumento de gestão ampliada introduzido para promover revisão e mudanças em um dado coletivo organizado deve ater-se não só à produção, mas também aos modos como esta se organiza em relação às demandas deordem subjetiva oriundas dos sujeitos ali inseridos ${ }^{28}$.

N esse caso, cabe ressaltar a dupla dimensão social da gestão, como ação estratégica e comunicativa dirigida a fins como a criação de consenso ativo entregerentes eprofissionais em processos coletivos de trabal ho e para o entendimento etrocas intersubjetivas na constituição de novos sujeitos das práticas institucionais de saúde. Ao se observar os sujeitos em ação e comunicação nas organizações, é possível aportar à interação social, identificar racionalidades presentes na gestão para as respostas às necessidades de saúde e valorizar a intersubjetividade na explicitação de conflitos e busca de entendimento ${ }^{29}$.

Sob este prisma, o processo avaliativo também éuma ação social da gestão desenvolvida em meios complexos, como programas ou serviços de saúde, nos quais não épossível atribuir significado específico a um elemento sem considerar a lógica e interferência de outros atores, sobretudo no contexto das ações programáticas e assistência integral à saúde. A pesar detoda a complexidade de atores e posições envolvidos no campo da avaliação, a mesma é voltada na maior parte das vezes somente para as lógicas regulatórias, econômicas ou mesmo técnico-gerencial, em detri- 
mento dos usuários, profissionais e parceiros comunitários.

É inegável a natureza política das práticas avaliativas e a emergência de relações de poder nos espaços onde estas se realizam é frequente, 0 que requer do sujeito avaliador atenção constante, de modo a evitar cumplicidades de diversas ordens ou quese venha a ceder frente às pressões administrativas ou tecnocráticas. 0 trabaIho desse ator social dentro do SUS não deve se limitar à execução de tarefas definidas por grupos particulares, num sistema que se pretende universal e equitativo, mas intercambiar ao máximo a diversidade imanente dos programas e serviços de saúde a serem avaliados ${ }^{28}$.

Logo, o controle do processo avaliativo por parte dos grupos de interesse, a consideração da complexidadee diversidade do contexto, as construções e informações daí produzidas e utilizadas deveriam se tornar diretrizes destinadas a contribuir para a ampliação do papel até agora restrito que o campo da avaliação tem promovido para a oferta programada das práticas integrais de saúde, como para a capacitação e desenvolvimento de todos os grupos implicados com o sistema público de saúde brasileiro.

Pires e Demo ${ }^{30}$, refletindo sobre as repercussões e possibilidades para o SUS no contexto do capitalismo tardio, apontam para a politicidade do cuidado como uma gestão emancipadora na (re)construção da autonomia de sujeitos, sejam esses gestores, profissionais ou usuários de saúde. Assim, seja no plano da assistência à saúde nas relações intersubjetivas do processo de trabalho, seja na formação de cidadãos em que a proteção se fortalece na construção da crítica ou, ainda, na gestão de políticas que tem como dimensão ética a questão pública controlada de mocraticamente, a politicidade do cuidado pode ser uma forma de mediação entre a tutela do Welfare State e a autonomia dos sujeitos no confronto de saberes e práticas para conhecer e cuidar melhor como para emancipar.

Abrindo parênteses, diríamos queemancipação significa que a vida coletiva é organizada de tal maneira em queo indivíduo seja capaz deexercer ação autônoma nos meios de sua vida social, onde ser independente supõe agir responsavelmente em relação aos outros indivíduos e reconhecer as obrigações coletivas. Partici pação livre e autônoma do cidadão na satisfação de suas necessidades básicas e bem-estar social como na organização política e destinos de uma comunidade, relevando, porém, os múltiplos condicionantes naturais, sociais e históricos que delimitam 0 agir humano.
Já a política-vida pressupõe certo nível de autonomia em relação às decisões políticas que derivam da liberdade deescolha edo poder gerador como capacidade transformadora, como a criação de formas equitativas de vida que promovam a autorrealização no âmbito da interação coletiva. Desenvolvendo assim uma ética relativa a preceitos de justiça e igualdade, de como devemos viver frente às questões existenciais do fenômeno social humano, numa ordem em que a reflexividade interliga o sujeito aos sistemas da modernidade tardia ${ }^{31}$.

Em um sentido mais amplo de proteção social, um Estado-nação não pode legislar nem intervir efetivamente sobre questões da políticavida de modo a tomar decisões relativas aos modos de vida da coletividade, sem que considere os conflitos de interesse evalores opostos presentes na sociedade capitalista que tende a gerar desigualdades no acesso a bens materiais tanto na escala global quanto em sociedades economicamente desenvolvidas.

Quanto à humanização do consumo e cotidiano em geral, refere-se à formação, construção e desfrute das necessidades reais dos indivíduos, mediante conquista de conteúdos adequados, distribuição democrática e acessos equitativos não mediados apenas pelo poder econômico do capitalismo. A seguridade integral da vida humana tem, por sua vez, como princípio maior a democratização das principais vias de acesso a bens e serviços de interesse à sociedade, como um sujeito coletivo da saúde ${ }^{32}$.

Tanto no cotidiano individual como nos espaços sociais e aparatos de Estado, deve dar-se uma integração de formas participativas de poder para a tomada de decisões de tal modo que toda a coletividade tenha o direito de ver seus interesses representados no seio do bem comum desse sujeito histórico popular ${ }^{32}$. Acrescenta-se que o pleno desenvolvimento humano, a partir deuma concepção de integralidade da vida ecom um sistema de saúde de qualidade e equânime conquistados democraticamente, é alicerce de qualquer proposta construtiva de saúde face à contrarreforma neoliberal com propósitos de tecnicizar a tudo e a todos.

Nessa perspectiva, o movimento de reforma sanitária na consolidação do SUS depende em grande parte da força mobilizadora com que a sociedade brasileira coloquea saúde dos cidadãos acima de todas outras racionalidades e, todavia, reconheça queas políticas públicas se constituem num meio poderoso para a efetiva defesa da vida. Devemos considerar então os movimentos dirigidos às políticas de proteção social, a viabilidade 
de sistemas regionalizados dando ênfase à integralidade das ações, a ampliação da qualidade dos serviços prestados na humanização do sistema e o desenvolvimento científico-tecnológico ancorado em projetos de ética e equidades frente ao poder neoliberal hegemônico ${ }^{33}$.

No que tange ao sujeito coletivo da saúde e sociedade, por meio das condições objetivas e subjetivas que gera, define tanto 0 seu conceito sanitário como os níveis de qualidade de vida que pretende alcançar. Nesse sentido, a saúde transcende e ultrapassa os limites setoriais, indo ao encontro das políticas públicas e sociais, envolvendo ações interinstitucionais e relações interculturais entre os atores históricos e epistêmicos. Logo, o padrão de saúde como impacto social também é informado e informa o conjunto de crenças e valores que igualmente incitam ou travam as conquistas coletivas, como os conflitos deinteresses e consciência sanitária dos sujeitos que repercutem de al gum modo na saúde da sociedade como um todo ${ }^{34}$.

As políticas públicas, por sua vez, correspondem às respostas sociais frente às condições de vida e seus determinantes, como diante da produção, distribuição e regulação de serviços e ambi entes que afetam a saúde das col etividades. Ao mesmo tempo, essas políticas, não se restringindo apenas às normas, diretrizes e regulamentos, implicam uma dada distribuição dos poderes políticos, institucionais, gerenciais e técnicos no âmbito setorial e no exercício da cultura, cidadania, ideologia ebem comum pela sociedade, expressando, pois, autonomia, transformação e legitimação entre os atores e sujeitos sociais ${ }^{35}$.

A partir dos anos noventa, sob a ótica político-institucional do SUS, a participação e controle social das decisões sobre as políticas e práticas de saúde têm conduzido a uma revalorização do planejamento, programação e avaliação em saúde, desde uma perspectiva estratégica, situacional, comunicativa egerencial. Emergindo, assim, as interfaces das pesquisas no campo dessas políticas com outros saberes e práticas em Saúde Pública, como educação em saúde, comunicação social, gestão da qualidadeem saúdee epidemiologia e serviços de saúde ${ }^{36}$.

A despeito da utilização da epidemiologia nos serviços de saúde, refere-se especialmenteàanálise das condições de vida e saúde de populações distintas com o propósito de alcançar uma maior efetividade na planificação e gestão do setor saúde, contribuindo assim para a identificação de prioridades e avaliação dos programas e serviços de saúde ${ }^{37}$. Já no âmbito da oferta organizada, espaço de articulação do enfoque epidemiológi- co, a programação e a execução das ações partiriam então da priorização dos problemas e necessidades de saúdeem territórios delimitados, como na proposta de reorganização das práticas sanitárias no contexto de construção do SU ${ }^{38,39}$.

Com efeito, isto diz respeito à própria dimensão operacional das práticas de saúde na organização social da produção e prestação de bens e serviços, correspondendo aos modos de combinar tecnologias, materiais enão materiais, utilizadas nos processos de trabal ho coletivo e resultando na oferta organizada e ações programáticas de saúde. Significando um conjunto articulado eintegrado de práticas destinadas ao controle decausas, riscos e danos à saúde, como na flexibilização da organização desse trabalho produtivo para 0 enfrentamento dos problemas priorizados nos diferentes momentos do processo saúde-doença. Todo esse referencial abrangente contempla, em última instância, a formulação de políticas públicas saudáveis e intervenção social organizada sobrea situação de saúde das coletividades nos seus distintos modos de andar a vida ${ }^{38}$.

Em suma, na recomposição das práticas de saúde no SUS, o repensar a epidemiologia como meio de trabalho significa concebê-la como uma "tecnologia não material", ou seja, uma ferramenta imprescindível de gestão em Saúde Pública. Assim, a epidemiologia como saber tecnológico pode ser utilizada como instrumento para a elaboração de políticas, planejamento e avaliação de saúde, como na organização do processo de trabalho produtivo e orientação programática em saúde ${ }^{29}$.

Quanto à vigilância da saúde, constitui-se de fato em uma estratégia de organização de políticas e práticas que assumem configurações específicas conforme a situação de saúde de diferentes coletividades. Alternativas mais abrangentes requerem tanto uma reflexão sobre os fundamentos teóricos que sustentam essas propostas de ação, como um escrutínio da situação concreta no sentido de contextualizar cadaintervenção concebida para que se al cancem os efeitos esperados sobre a realidade em questão. Trata-se de produzir saberes que contribuam efetivamente para reorientar os modos tecnológicos de intervenção e enfrentar assim as questões problemáticas do real, quanto da construção de propostas que não se contentem com as aparências do empírico ou com as crenças, mas quese el evem à essência dos fenômenos mediantetrabalho teórico eepistemológico capaz de conduzir ao concreto pensado ${ }^{5}$.

Por fim, o campo da Saúde Coletiva abrange também o estudo das condições de saúde, a organização do processo detrabalho, a implementação 
de políticas públicas, como a avaliação das práticas de saúde. Como saber, articula-se num eixo transinterdisciplinar constituído pela epidemiologia, planejamento e ciências sociais em saúde, com enfoque na geografia, história, sociologia, ciências políticas, dentre outras. Enquanto prática, propõe mudanças no modelo assistencial de saúde, relevando uma consciência sanitária construtiva eparticipação social no processo de reorientação das políticas transetoriais, tendo em vista a melhoria dos níveis de saúde e da qual idade de vida.

Face ao aporte das relações complexas entre necessidades epráticas de saúde, por meio deuma prática integradora de saberes em vista da ação, a abordagem multidimensional nos ajuda a compreender a dinâmica do processo saúde-doença tomado, estruturalmente, sob certos aspectos significantes dos contextos político, social e econômico. Referimo-nos à relevância deconstruir- mos e adotarmos modelos interativos de saberes e práticas que se compactuem aos problemas enecessidades da própria realidade social de saúde, uma prática interdisciplinar que, privilegiando as formas de repensar a Saúde Coletiva, na produção e prestação de serviços, concretiza-se numa atuação em que interagem os sujeitos do saber e atores sociais da ação40.

Enfim, ao transitarmos sob uma perspectiva sistêmica não pragmática, esperamos ter contribuído para os debates e discussões inesgotáveis sobre as possi bilidades de apreensão das dimensões do objeto-complexo da pesquisa avaliativa em saúde, isto é, dentreas ditas interfaces dialéticas do real sócio-histórico construído por atores da vida coletiva: saber e ação; social e sanitário; equidade equalidade; promoção e proteção; contexto e processo; sujeito e cuidado, ou ainda, políticas e práticas.

\section{Colaboradores}

ALV Arreazae JC M oraes participaram igualmente de todas as etapas da elaboração do artigo.

\section{Referências}

1. Vieira-da-Silva LM, Formigle VLA. Avaliação em saúde: limites e perspectivas. Cad Saude Publica 1994; 10(1):80-91.

2. Paim JS, Almeida-Filho N. Saúde Coletiva: uma nova saúde pública ou campo aberto a novos paradigmas? Rev. Saude Publica 1998; 32(4):299-316.

3. Muñoz F, López-Acuña $D$, Halverson P, Guerra de Macedo C, Hanna W, Larrieu M, U billa S, Zeballos $J$ L. Las funciones esenciales de la salud pública: un tema emergente en las reformas del sector de la salud. Rev Panam Salud Publica 2000; 8(1/2):126-134.

4. Drumond Jr M. Epidemiologia nos municípios: muito além das normas. São Paulo: Hucitec; 2003. p. 53-66.

5. Paim JS. Vigilância da Saúde: dos modelos assistenciais para a promoção da saúde. In: Czeresnia D, Freitas CM, organizadores. Promoção da Saúde: conceitos, reflexões e tendências. Rio de Janeiro: Fiocruz; 2003. p. 161-174.

6. Campos GWS. Saúde pública e saúde coletiva: campo e núcleo de saberes e práticas. Cien Saude Colet 2000; 5(2):219-230.

7. Schraiber LB, Peduzzi M, Sala A, Nemes MIB, Castanhera ERL, Kon R. Planejamento, gestão e avaliação em saúde: identificando problemas. Cien Saude Colet 1999; 4(2):221-242.

8. Patton M Q. Utilization-focused evaluation: the new century text. Thousand O aks: Sage Publications; 1997. 
9. Contandriopoulos AP, Champagne F, Denis JL, Pineault R. A avaliação na área da saúde: conceitos e métodos. In: Hartz ZM A, organizadora. Avaliação em saúde: dos modelos conceituais à prática na análise da implantação de programas. Rio de Janeiro: Fiocruz; 1997. p. 29-47

10. Deslandes SF. Concepções em pesquisa social: articulações com o campo da avaliação em serviços de saúde. Cad Saude Publica 1997; 13(1):103-107.

11. Patton M Q. Evaluation, knowledge management, best practices, and high quality lessons learned. Ame J Evaluation 2001; 22(3):329-336.

12. Vieira-da-Silva LM. Conceitos, abordagens e estratégias para a avaliação em saúde. In: H artz ZM A, Vieira-da-Silva LM, organizadoras. Avaliação em saúde: dos modelos teóricos à prática na avaliação de programas e sistemas de saúde. Rio de Janeiro: Fiocruz; 2005. p. 15-39.

13. Lopes RM, Vieira-da-Silva LM, Hartz ZM A. Teste de uma metodologia para avaliar a organização, acesso e qualidade técnica do cuidado na atenção à diarréia na infância. Cad Saude Publica 2004; 20(Supl 2) :283-297.

14. Donabedian A. The seven pillars of quality. Arch Pathol Lab M ed 1990; 114:1115-1118.

15. M aynard A, M cdaid D. Evaluating health interventions: exploiting potential. Health Policy 2003; 63:215-226.

16. Vuori H. Estratégias para a melhoria da qualidade dos cuidados em saúde. In: Seminário de Avaliação dos Serviços de Saúde: aspectos metodológicos; 1988; Rio de Janeiro. p. 17-24.

17. Mattos RA. A integralidade na prática (ou sobre a prática da integralidade). Cad Saude Publica 2004; 20(5):1411-1416.

18. Crevelim MA, Peduzzi M . A participação da comunidade na equipe de saúde da família: como estabelecer um projeto comum entre trabalhadores e usuários? Cien Saude Colet 2005; 10(2):323-331.

19. Serapioni M. Avaliação da qualidade em saúde: a contribuição da sociologia em saúde para a superação da polarização entre a visão dos usuários e a perspectiva dos profissionais de saúde. Saúde Debate 1999; 23(53):81-92.

20. Frias PG, Lira PIC, Hartz ZMA. Avaliação da implantação de um projeto para redução da mortalidade infantil. In: Hartz ZM A, Vieira-da-Silva LM, organizadoras. Avaliação em saúde: dos modelos teóricos à prática na avaliação de programas e sistemas de saúde. Rio de Janeiro: Fiocruz; 2005. p. 151-206.

21. Vieira-da-Silva LM, H artz ZM A, Chaves SCL, Pontes-Silva GA. M etodologia para análise da implantação de processos relacionados à descentralização da atenção à saúde no Brasil. In: Hartz ZMA, Vieira-da-Silva LM , organizadoras. Avaliação em saúde: dos modelos teóricos à prática na avaliação de programas e sistemas de saúde. Rio de Janeiro: Fiocruz; 2005. p. 207-253.

22. Hartz ZM A. Explorando novos caminhos na pesquisa avaliativa das ações de saúde. In: Hartz ZM A organizadora. Avaliação em saúde: dos modelos conceituais à prática na análise da implantação de programas. Rio de Janeiro: Fiocruz; 1997. p. 19-28.
23. M edina M G, Pontes-Silva GA, Aquino R, Hartz ZMA. U so de modelos teóricos na avaliação em saúde: aspectos conceituais e operacionais. In: H artz ZM A, Vieira-da-Silva LM, organizadoras. Avaliação em saúde: dos modelos teóricos à prática na avaliação de programas e sistemas de saúde. Rio de Janeiro: Fiocruz; 2005. p. 41-63.

24. Hortale VA, Conill EM, Pedroza M. Desafios na construção de um modelo para análise comparada da organização de serviços de saúde. Cad Saude Publica 1999; 15(1):79-88.

25. Carvalho Al, Bodstein RC, Hartz ZM A, M atida AH. Concepts and approaches in the evaluation of health promotion. Cien Saude Colet 2004; 9(3):521-529.

26. Viacava F, Almeida C, Caetano R, Fausto M, Macinko J, Martins $M$, Noronha JC, Novaes HM D, Oliveira ES, Porto SM, Vieira-da-Silva LM, Szwarcwald CL. U ma metodologia de avaliação do desempenho do sistema de saúde brasileiro. Cien Saude Colet 2004; 9(3):711-724.

27. Campos GWS, Barros RB, Castro AM . Avaliação de política nacional de promoção da saúde. Opinião. Cien Saude Colet 2004; 9(3):745-749.

28. Furtado JP. Um método construtivista para a avaliação em saúde. Cien Saude Colet 2001; 6(1):165-181.

29. Paim JS. Epidemiologia e planejamento: recomposição das práticas epidemiológicas na gestão do SUS. Cien Saude Colet 2003; 8(2):557-567.

30. Pires MRG, Demo P. Políticas de saúde e crise do Estado de Bem-Estar: repercussões e possibilidades para o sistema único de saúde. Saude soc. 2006; 15(2):56-71.

31. Giddens A. M odernidade e identidade. Rio de Janeiro: Jorge Zahar; 2002. p. 193-212.

32. Breilh J. Derrota del conocimiento por la información: una reflexión necesaria para pensar en el desarrollo humano y la calidad de vida desde una perspectiva emancipadora. Cien Saude Colet 2000; 5(1):99-114.

33. Campos GWS. Reforma política e sanitária: a sustentabilidade do SUS em questão? Cien Saude Colet 2007; 12(2):301-306.

34. M inayo MCS. Estrutura e sujeito, determinismo e protagonismo histórico: uma reflexão sobre a práxis da saúde coletiva. Cien Saude Colet 2001; 6(1):7-19.

35. Paim JS. Equidade e reforma em sistemas de serviços de saúde: o caso do SUS. Saude soc. 2006; 15(2):34-46.

36. Teixeira CF. Investigação em sistemas e serviços de saúde: novos problemas e objetos, abordagens e estratégias. Saude soc. 1997; 6(1):11-23.

37. Castellanos PL. Epidemiología y organización de los servicios. In: OPS/OMS, organizador. La formación en epidemiología para el desarrollo de los servicios de salud. Washington, D.C.: OPS/OM S; 1987. p. 30-40. [Serie Desarrollo de Recursos Humanos no 88]

38. Teixeira CF, Paim JS, Vilasbôas AL. SUS, modelos assistenciais e vigilância da saúde. IESU S 1998; 7(2):7-28

39. Paim JS. A reforma sanitária e os modelos assistenciais. In: Rouquayrol MZ, Almeida-Filho N, organizadores. Epidemiologia e Saúde. 5a ed. Rio de Janeiro: Medsi; 1999. p. 473-487.

40. Nunes ED. Interdisciplinaridade: conjugar saberes. Saúde D ebate 2002; 26(62):249-258.

Artigo apresentado em 19/11/2007

Aprovado em 28/04/2008 